\title{
Mechanical and Physicochemical Properties of 3D-Printed Agave Fibers/Poly(lactic) Acid Biocomposites
}

\author{
Valeria Figueroa-Velarde, Tania Diaz-Vidal, Erick Omar Cisneros-López $\mathbb{D}^{\mathbb{B}}$, Jorge Ramón Robledo-Ortiz $\mathbb{C}^{\mathbb{B}}$, \\ Edgar J. López-Naranjo, Pedro Ortega-Gudiño (i) and Luis Carlos Rosales-Rivera *(i)
}

University Center of Exact Sciences and Engineering (CUCEI), University of Guadalajara, Guadalajara 44430, Mexico; valeria.fvelarde@alumnos.udg.mx (V.F.-V.); taniadzv@gmail.com (T.D.-V.); erick.cisneros@academicos.udg.mx (E.O.C.-L.); jorge.robledo@academicos.udg.mx (J.R.R.-O.); edgar.lopezn@academicos.udg.mx (E.J.L.-N.); pedro.ogudino@academicos.udg.mx (P.O.-G.)

* Correspondence: carlos.rosales@academicos.udg.mx; Tel./Fax: +52-3313-7859-00 (ext. 27590)

\section{check for}

updates

Citation: Figueroa-Velarde, V.; Diaz-Vidal, T.; Cisneros-López, E.O.; Robledo-Ortiz, J.R.; López-Naranjo, E.J.; Ortega-Gudiño, P.; RosalesRivera, L.C. Mechanical and Physicochemical Properties of 3D-Printed Agave Fibers/Poly(lactic) Acid Biocomposites. Materials 2021, 14, 3111. https://doi.org/10.3390/ ma14113111

Academic Editor: Stephan Rudykh

Received: 28 April 2021

Accepted: 1 June 2021

Published: 5 June 2021

Publisher's Note: MDPI stays neutral with regard to jurisdictional claims in published maps and institutional affiliations.

Copyright: (c) 2021 by the authors. Licensee MDPI, Basel, Switzerland. This article is an open access article distributed under the terms and conditions of the Creative Commons Attribution (CC BY) license (https:// creativecommons.org/licenses/by/ $4.0 /)$.

\begin{abstract}
In order to provide a second economic life to agave fibers, an important waste material from the production of tequila, filaments based on polylactic acid (PLA) were filled with agave fibers $(0,3,5,10 \mathrm{wt} \%)$, and further utilized to produce biocomposites by fused deposition modeling (FDM)-based 3D printing at two raster angles $\left(-45^{\circ} / 45^{\circ}\right.$ and $\left.0^{\circ} / 90^{\circ}\right)$. Differential scanning calorimetry, water uptake, density variation, morphology, and composting of the biocomposites were studied. The mechanical properties of the biocomposites (tensile, flexural, and Charpy impact properties) were determined following ASTM international norms. The addition of agave fibers to the filaments increased the crystallinity value from 23.7 to $44.1 \%$. However, the fibers generated porous structures with a higher content of open cells and lower apparent densities than neat PLA pieces. The printing angle had a low significant effect on flexural and tensile properties, but directly affected the morphology of the printed biocomposites, positively influenced the impact strength, and slightly improved the absorption values for biocomposites printed at $-45^{\circ} / 45^{\circ}$. Overall, increasing the concentrations of agave fibers had a detrimental effect on the mechanical properties of the biocomposites. The disintegration of the biocomposites under simulated composting conditions was slowed 1.6-fold with the addition of agave fibers, compared to neat PLA.
\end{abstract}

Keywords: agave fibers; 3D printing; fused deposition modeling; poly(lactic) acid; biocomposites

\section{Introduction}

Among the available rapid prototyping or additive manufacturing technologies, printing based on fused deposition modeling (FDM) using thermoplastics is the best for modeling possibilities, mainly due to its simplicity, versatility, low economic impact, and widespread applicability [1]. FDM, also known as 3D printing, allows threedimensional figures to be obtained at high speed and precision, based on the extrusion of a polymer filament in a layer-by-layer arrangement ( $X$ and $Y$ axes) on top of a movable plate ( $z$ axis), until a 3D structure is obtained [2]. These complex figures can be produced in less time, as the prior formation of a mold is not required [3]. FDM applications have seen a predominant growth in personal prototyping fabrication, mainly due to a sharp cost reduction of FDM machines [4]. However, commercial FDM applications are still leading the market, mainly for the formation of automotive parts and aerospace prototypes [5], electronic devices, house construction, among others [6,7]. Promising results have also been found in the field of medicine for the production of biomedical devices and materials, such as bone replacement scaffolds [8-10].

Common polymer matrices employed in FDM techniques include acrylonitrile butadiene styrene (ABS), polycarbonates (PC), polyamides, polystyrene (PS), polymethyl methacrylate (PMMA), polyethylene (PE), and polylactic acid (PLA) [11]. Recently, efforts have been focused on the production and use of sustainable and renewable bio- 
plastics (such as PLA) for a wide variety of applications, from packaging to engineering, and biomedical devices, replacing petroleum-based plastics [12-14]. PLA is a thermoplastic biopolymer belonging to the family of aliphatic polyesters. PLA is obtained by fermentation of renewable resources such as corn or agricultural waste [15]. Unlike other polymers, PLA is considered a sustainable material as it can be compostable, which can be further utilized to promote a new cycle of agricultural products for future conversion into PLA [16].

The innate versatility of rapid prototyping enables the fabrication of high-resolution parts reinforced with diverse materials such as ceramics, metals, minerals, and natural fibers $[6,17]$. Traditional reinforcing materials such as glass or carbon fibers allow the fabrication of composites with superior mechanical properties; however, their inherent inconvenience relies on the difficulty of recycling their components once the material is no longer purposeful [6]. In this sense, the addition of natural fibers as reinforcers in composite materials has gained great attention due to their "green" character, cheaper cost, and high availability $[6,18]$. The production of biocomposites from renewable sources, recycled fibers, industrial co-products, and forestry and agricultural residues is an environmentally friendly approach for the production of materials with a lower carbon footprint, reducing the ecological impact of waste materials [6]. Fabrication of 3D-printed PLAbased biocomposites using natural fibers includes bamboo powder [19], wood flour [20], wood [21], kraft lignin [22], and cork [23], among others [24].

In 2020, the Tequila Regulatory Council estimated the production of 523,600 tons of bagasse from Agave tequilana Weber var. Azul. Thus, $1.4 \mathrm{~kg}$ of agave waste is created per liter of produced tequila [25,26], posing an extreme environmental issue. Several researchers have joined efforts to find low-cost, environmentally friendly alternative uses to agave wastes. Agave residues can be treated to obtain fibers that are typically short and elliptically shaped, 10-12 cm long, and with a diameter of $592.34 \mu \mathrm{m}$ [27]. Agave fibers have been previously used for the obtaining of biocomposites. Torres-Tello produced biocomposites from agave fibers and polyhydroxybutyrate (PHB) with increased tensile and flexural moduli [28]. Recently, PLA- and agave fiber-reinforced biocomposites were produced by dry-blending and rotational molding, demonstrating the production of biodegradable, low-cost biocomposites [29]. However, to date, there have been no published reports concerning reinforcement with agave fibers to produce filaments for an FDM process for a final application in 3D printing. As agave fibers are waste material, the addition of waste fibers to matrices, which are usually expensive, can help to diminish the cost of the material. This offers the opportunity to generate novel materials suitable for 3D printing with certain advantages, such as lightness, sustainability, biodegradability, and low cost (compared to neat polymeric materials).

The present work describes the development of a biodegradable filled material for further use as filaments in a 3D printer. Agave fibers (mesh 100-140) were used as a filler material in a PLA matrix. The modified variables were weight percentage $(0,3,5$, and $10 \mathrm{wt} \%$ ) and FDM deposition angle $\left(-45^{\circ} / 45^{\circ}\right.$ and $\left.0^{\circ} / 90^{\circ}\right)$. Differential scanning calorimetry (DSC), water uptake, density variation, and biodegradability of the biocomposites were studied, whereas morphological characterization was performed via SEM. The mechanical properties were studied following the ASTM international norms for tensile, flexural, and Charpy impact. The effects of FDM process parameters on the tensile properties of fabricated agave fiber/PLA biocomposites were also investigated.

\section{Materials and Methods}

\subsection{Materials}

Polylactic acid 3251D (PLA, density $=1.24 \mathrm{~g} \mathrm{~cm}^{-3}$, melt flow index $=80 \mathrm{~g} / 10 \mathrm{~min}^{-1}$, $\left(2.16 \mathrm{~kg}, 210^{\circ} \mathrm{C}\right)$, according to the provided technical data sheet), supplied in spherical pellets, was obtained from Nature Works LLC (Minnetonka, MN, USA). Agave fibers (AF) from A. tequilana Weber var. Azul were obtained from a local tequila company (Mundo Agave, Tequila, Mexico). 


\subsection{Agave Fiber Cleaning and Sieving}

AF were prepared as reported by Pérez-Fonseca et al. [30] with minor modifications. Briefly, the pithy fibers were hydrated for $24 \mathrm{~h}$, and next, the pith was separated from the fiber with a two-disk (diameter, $30 \mathrm{~cm}$ ) Sprout-Waldron D2A509NH refiner (Muncey, PA, USA). The separated AF were then centrifuged for $20 \mathrm{~min}$ at $3750 \times \mathrm{g}$ rpm to remove excess water, and dried outdoors. Finally, the AF were ground with a ball mill and sieved using a Ro-Tap RX-29 (Oelde, Germany) with a \#100-140 sieve fraction.

\subsection{AF/PLA Filament Preparation}

Samples of AF with different weight percentages (0, 3, 5, $10 \mathrm{wt} \%)$ and PLA were prepared using a total weight of $1000 \mathrm{~g}$ for each composition (Table S1, Supplementary Materials). Next, the materials were dry-blended using a high shear mixer JR Torrey LP-12 (Monterrey, Mexico) for $2 \mathrm{~min}$ and oven-dried at $60{ }^{\circ} \mathrm{C}$ for $24 \mathrm{~h}$. The filaments were then produced by extrusion using a twin-screw extruder Leistritz Micro 27 GL/GG 32D (Nuremberg, Germany) with a screw rotational speed of $65 \mathrm{rpm}$. A forward ramp temperature profile with nine zones was set to $160 / 160 / 165 / 165 / 170 / 170 / 175 / 175 / 175{ }^{\circ} \mathrm{C}$. The final filament had a diameter of $1.7 \pm 0.07 \mathrm{~mm}$.

\subsection{Differential Scanning Calorimetry (DSC)}

A differential scanning calorimeter (TA Instruments Q100 (New Castle, DE, USA)) was used to study the thermal properties of the agave-fibers/PLA filaments. The specimens were cut to a homogenous weight of $3-5 \mathrm{mg}$ and heated once from 25 to $200^{\circ} \mathrm{C}$

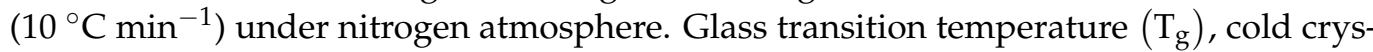
tallization temperature $\left(\mathrm{T}_{\mathrm{cc}}\right)$, melting temperature $\left(\mathrm{T}_{\mathrm{m}}\right)$, enthalpy of cold crystallization $\left(\Delta \mathrm{H}_{\mathrm{cc}}\right)$, and melting enthalpy $\left(\Delta \mathrm{H}_{\mathrm{m}}\right)$ were determined from the DSC curves with TRIOS TA software (Version 4.4.0.41651) [31]. Values of $\mathrm{T}_{\mathrm{m}}$ and $\Delta \mathrm{H}_{\mathrm{m}}$ were obtained from the peak temperature and area of the melting endotherm, respectively.

The crystallinity level $\left(X_{c}\right)$ of the samples was evaluated from their corresponding melting enthalpies using Equation (1) [32],

$$
\mathrm{X}_{\mathrm{c}}(\%)=\frac{\Delta \mathrm{H}_{\mathrm{m}}-\Delta \mathrm{H}_{\mathrm{cc}}}{\Delta \mathrm{H}^{\circ}} \times \frac{100}{\mathrm{w}}
$$

where $\Delta \mathrm{H}^{\circ}$ (PLA) is the melting enthalpy $\left(93.7 \mathrm{~J} \mathrm{~g}^{-1}\right.$ ) of $100 \%$ crystalline (perfect crystal) PLA, and $\mathrm{w}$ is the weight fraction of PLA in the biocomposites.

\subsection{Fused Deposition Modeling/3D Printing}

Computer aided designs (CAD) were drawn and visualized in Google SketchUp (Version 16.0.14004, Mountain View, CA, USA) [33] with dimensions following the ASTM standards for each test/characterization. The designs were transferred to a printable format using the Hot-World GmbH \& Co. Repetier-Host software [34] (Version 1.6.2, Willich, Germany) and printed with a Wanhao Duplicator 4 (Jinhua, China), which has a layer resolution of $100 \mu \mathrm{m}$, according to the provided user manual specifications. The maximum printing size was $25 \times 25 \times 3 \mathrm{~mm}^{3}$ (length, width, and height, respectively) with a layer height of $0.3 \mathrm{~mm}$. The minimum resolution of the design and dimensions of the final pieces are depicted in Figure S1, Supplementary Materials. The AF/PLA filaments with different agave fiber weight percentages $(0,3,5,10 \mathrm{wt} \%)$ were printed using a nozzle temperature of $190{ }^{\circ} \mathrm{C}$, a bed temperature of $70^{\circ} \mathrm{C}$ and filled using a crosshatch pattern. The infill was set to $100 \%$, with a crosshatch angle of $-45^{\circ} / 45^{\circ}$ and $0^{\circ} / 90^{\circ}$. The printing speed was $50 \mathrm{~mm} \mathrm{~s}^{-1}$. 


\subsection{Density and Porosity}

Experimental density $\rho_{\text {exp }},\left(\mathrm{g} \mathrm{cm}^{-3}\right)$ calculations were performed for AF/PLA printed pieces of $2.5 \times 2.5 \times 0.3 \mathrm{~cm}^{3}$. The theoretical density was obtained from Equation (2).

$$
\mathrm{P}_{\mathrm{th}}=\frac{1}{\frac{\mathrm{x}_{\mathrm{PLA}}}{\rho_{\mathrm{PLA}}}+\frac{\mathrm{x}_{\mathrm{AF}}}{\rho_{\mathrm{AF}}}}
$$

where $\rho_{\text {th }}$ is the theoretical density in $\mathrm{g} \mathrm{cm}^{-3}, \mathrm{x}_{\mathrm{PLA}}, \mathrm{x}_{\mathrm{AF}}$ are the weight fraction of PLA and $\mathrm{AF}$, respectively, and $\rho_{\mathrm{PLA}}, \rho_{\mathrm{AF}}$ are the experimental densities of PLA and AF, respectively, obtained via a 3P Instruments gas pycnometer Ultrapyc 1200e (Odelzhausen, Germany) with nitrogen in the chamber cell.

The porosity was calculated comparing the experimental and theoretical density as in [35], using Equation (3). All the experiments were performed using four samples for each composition.

$$
\text { Porosity }(\%)=\frac{\rho_{\text {th }}-\rho_{\text {exp }}}{\rho_{\text {th }}}
$$

\subsection{Water Absorption}

The water absorption of AF/PLA printed composites was measured following the ASTM D570-03 standard at room temperature. Prior, AF/PLA printed pieces of $25 \times 25 \times 3 \mathrm{~mm}^{3}$ were dried in an oven at $60^{\circ} \mathrm{C}$ and then weighed. Then, the samples were submerged in distilled water and removed after 2, 4, 6, and $24 \mathrm{~h}$ for 50 days, cleaned of excess water with a soft cotton cloth, and weighed for weight increment monitoring. All the experiments were performed using four samples for each composition.

\subsection{Mechanical Properties}

Tensile tests were carried out following the ASTM International D638-03 standard using type IV specimens. The testing was performed with an INSTRON 3345 (Norwood, MA, USA) with a $5 \mathrm{kN}$ load cell at a crosshead speed of $5 \mathrm{~mm} / \mathrm{min}$, subjecting a total of 8 specimens to uniaxial tensile stress.

Flexural properties were obtained according to the ASTM International D790-03 standard. The three-point flexural testing was performed with the same machine used for tensile tests at a crosshead rate of $2 \mathrm{~mm} / \mathrm{min}$ using 8 specimens of $70 \times 12.7 \times 3 \mathrm{~mm}^{3}$.

Impact strength tests were carried out in a Charpy impact tester (Tinius Olsen IT104 (Horsham, PA, USA)) using a pendulum of $242 \mathrm{~g}$ (1.22 J). Printed pieces were prepared according to the ASTM International D6110-04 standard. A manual sample notcher (Instron CEAST 6897 (Norwood, MA, USA)) was used to prepare the samples at least $24 \mathrm{~h}$ before testing. Each value represents the average of 8 notched samples. All samples were tested at room temperature $\left(\sim 25^{\circ} \mathrm{C}\right)$. The load direction applied on the specimens with respect to the printing angle for the different mechanical tests is shown in Figure S2, Supplementary Materials.

\subsection{Disintegration under Simulated Composting Conditions}

Gravimetric weight loss of AF/PLA printed pieces was performed following the ISO standard 20200:2004. Initially, $25 \times 25 \times 3 \mathrm{~mm}^{3}$ pieces were oven-dried at $60^{\circ} \mathrm{C}$, until a constant weight was achieved. Then, the dried pieces were deposited under simulated composting conditions, with $50 \%$ organic matter, $58{ }^{\circ} \mathrm{C}$ and $>40 \%$ of humidity for 49 days. Every 7 days, the composted specimens were withdrawn, cleaned, dried at $60{ }^{\circ} \mathrm{C}$ and weighed again to study the material weight lost. All experiments were performed by triplicate using 8 specimens for each composition.

\subsection{Morphological Characterization}

Micrographs were obtained with a field emission scanning electron microscope (FESEM) (Tescan MIRA3 LMU (Brno, Czech Republic)) using a laser beam of $10 \mathrm{kV}$ accelerating 
voltage. Prior, the samples were immersed in liquid nitrogen, fractured, and then coated with a thin conductive layer of Au under vacuum using an SPI Module Sputter Coater (West Chester, PA, USA) for $60 \mathrm{~s}$.

\subsection{Statistical Analysis}

The mechanical test data were subjected to an analysis of variance (ANOVA) to determine if the differences were statistically significant $(p \leq 0.05)$ between the evaluated factors and their levels. For each test, 8 repetitions were performed (8 specimens were fractured), and the two end values were discarded.

A multifactorial design with two factors-fiber content and printing angle-was designed with four and two levels, respectively. To analyze the behavior of the effects of fiber content, printed angle, and their interactions, the mean comparison was analyzed through the LSD test. The analyses were performed using Statgraphics Centurion XV (The Plains, VA, USA) Version 15.2.06 [36].

\section{Results and Discussion}

\subsection{SEM Micrographs of Agave Fibers and AF/PLA Filaments}

The surface morphology of AF is detailed in Figure 1. AF were used without any chemical treatment; therefore, impurities and debris can be observed in Figure 1A. Before filament preparation, the diameter and length of the AF were measured from SEM micrographs. Properties such as fiber length and fiber orientation can alter the final mechanical properties of a given composite [29]. Damaged fibers by compression-molding show a steady reduction in fiber length, thus compromising its filler ability [37]. The measured area was converted to an equivalent diameter of a circle to obtain the fiber diameter. Clean AF (400 fibers counted, Figure 1A) showed an equivalent diameter of $46.6 \pm 20.9 \mu \mathrm{m}$ and a length of $246 \pm 92 \mu \mathrm{m}$ (aspect ratio, L/D, of 5.2). After the sieving process (Figure 1B), $\mathrm{AF}$ had a diameter of $37.7 \pm 16.6 \mu \mathrm{m}$ and a length of $255 \pm 108 \mu \mathrm{m}$ (capillary L/D ratio of 6.7). Sieved AF showed a difference in $\mathrm{L} / \mathrm{D}$ aspect ratio compared to clean $\mathrm{AF}$ due to a decrease in their diameter. After the extrusion process, the AF/PLA filaments with $10 \mathrm{wt} \%$ agave content were frozen with liquid nitrogen, and then, the filament diameter (100 fibers counted) was measured directly from cryofracture SEM micrographs (Figure 2). The obtained diameter was $36.6 \pm 16 \mu \mathrm{m}$. However, the fiber length in the final printed piece could not be measured. Nonetheless, damage to some extent in the length is expected [37].

\subsection{Thermal Properties and Crystallinity of Agave Fibers/PLA Filaments}

Values for glass transition $\left(\mathrm{T}_{\mathrm{g}}\right)$, crystallization $\left(\mathrm{T}_{\mathrm{c}}\right)$ and melting temperatures $\left(\mathrm{T}_{\mathrm{m}}\right)$ were obtained from the DSC curves for neat PLA and AF/PLA filaments (Table 1). While $T_{g}$ and $\mathrm{T}_{\mathrm{c}}$ values diminished with the addition of $A F, \mathrm{~T}_{\mathrm{m}}$ values of filaments showed a minor increase with respect to PLA. The $0-3 \mathrm{wt} \%$ and $5-10 \mathrm{wt} \%$ AF/PLA filaments showed a $5 \%$ and $11 \%$ reduction in $T_{c}$ values, respectively, in comparison to neat PLA. $T_{g}$ values for neat PLA and $0 \mathrm{wt} \% \mathrm{AF} / \mathrm{PLA}$ filaments were similar $\left(58.9^{\circ} \mathrm{C}\right.$ and $59.1{ }^{\circ} \mathrm{C}$, respectively), whereas $\mathrm{T}_{\mathrm{g}}$ values for $3-10 \mathrm{wt} \%$ AF/PLA filaments showed no significant differences $\left(57.9^{\circ} \mathrm{C}\right.$, $57.7{ }^{\circ} \mathrm{C}$, and $57.2{ }^{\circ} \mathrm{C}$ for $3 \mathrm{wt} \%, 5 \mathrm{wt} \%$, and $10 \mathrm{wt} \%$ AF/PLA composites, respectively). The DSC thermal transitions for neat PLA and all AF/PLA filaments are detailed in Figure S3, Supplementary Materials. The crystallinity values of PLA and AF/PLA filaments were obtained from $\Delta \mathrm{H}_{\mathrm{c}}$ and $\Delta \mathrm{H}_{\mathrm{f}}$ values. After the extrusion process, the crystallinity value of $0 \mathrm{wt} \% \mathrm{AF} / \mathrm{PLA}$ filaments increased from $11.6 \%$ to $23.7 \%$ (Table 1 ), which can be attributed to the cooling rate of the filaments after the extrusion stage [38]. The low crystallinity value observed for neat PLA pieces is explained by PLA stoichiometry (L and D isomers) and the slow crystallization rate of PLA [39]. High D content gives amorphous extruded materials. In this work, the low crystallinity value of PLA 3251 is due to the presence of $1.4 \%$ of the D-isomer.

The crystallinity values of AF/PLA filaments were similar for biocomposites of between $0-3 \mathrm{wt} \%$ and $5-10 \mathrm{wt} \%$ AF content. However, the values increased up to $50 \%$ and up 
to $71 \%$ for $0-3 \mathrm{wt} \%$ and $5-10 \mathrm{wt} \%$ AF content, respectively, compared to neat PLA. This effect can be attributed to the nucleation effect caused by the presence of AF [40]. Similarly, Teixeira et al. found that after adding $10 \mathrm{wt} \%$ of thermoplastic bagasse to PLA biocomposites, their crystallinity increased from 1.6 to $17.5 \%$, due to the presence of cellulosic fibers from cassava bagasse [41].
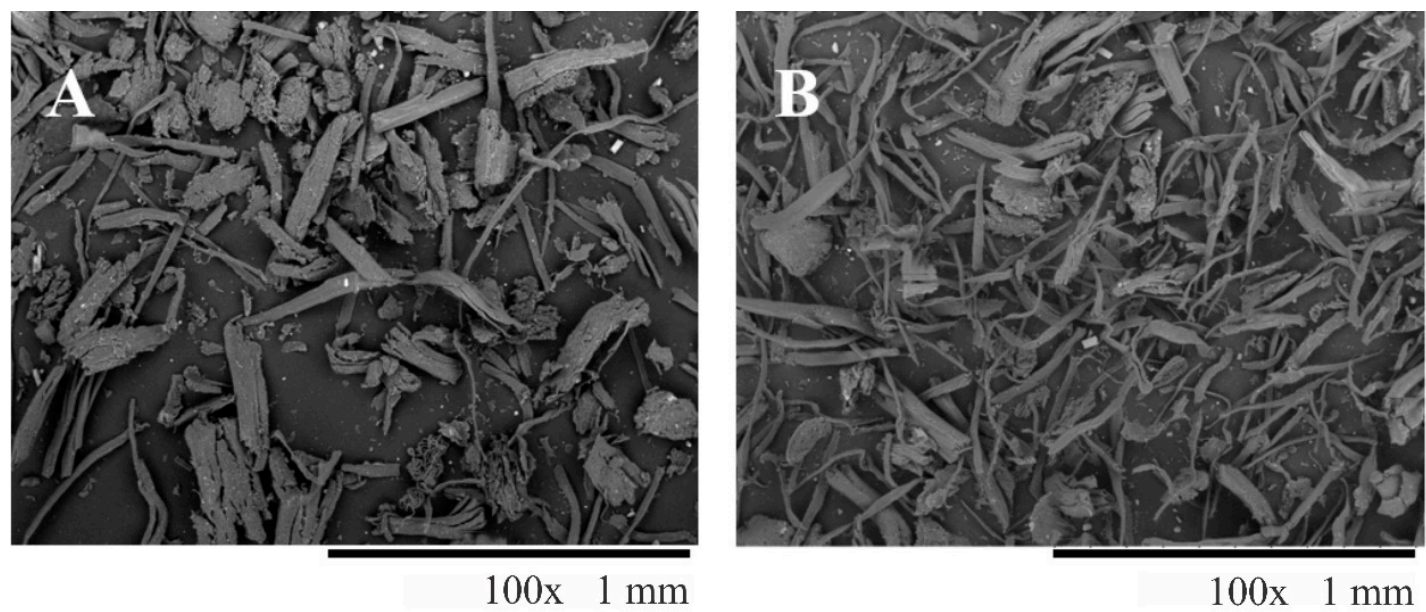

Figure 1. SEM micrographs of agave fibers (AF) used for biocomposite preparation (A) after sieving, and (B) after high shear mixing process $(100 \times$ magnification).

Agave fiber content $w t \%$

$0 \%$

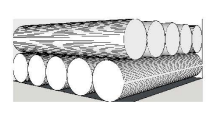

$-45 / 45^{\circ}$
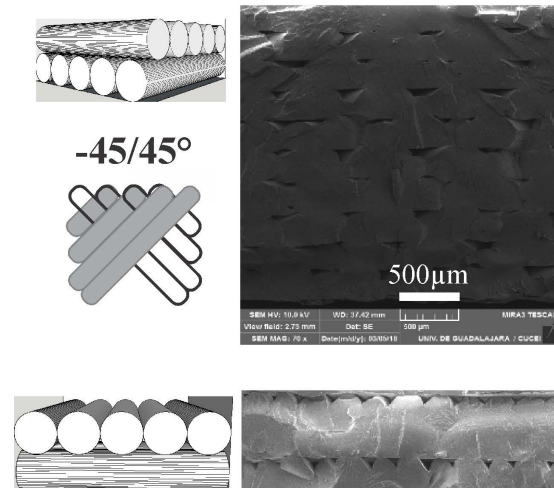

$0 / 90^{\circ}$
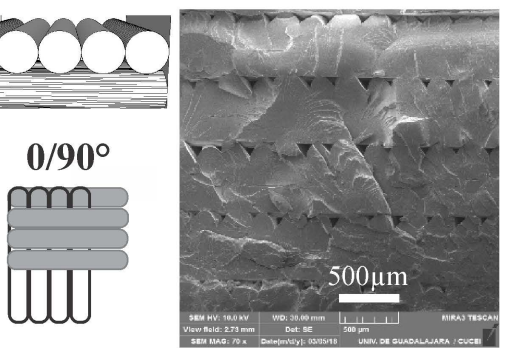

$3 \%$
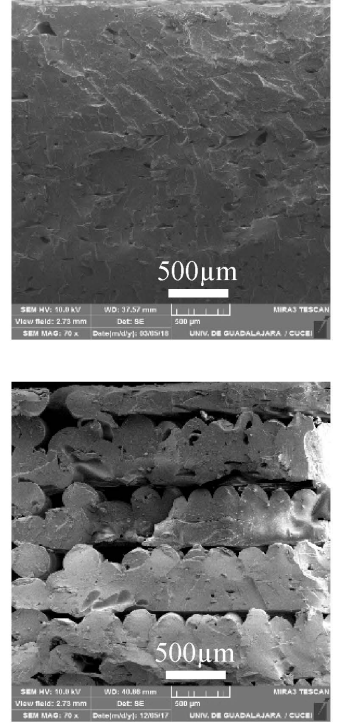

$5 \%$
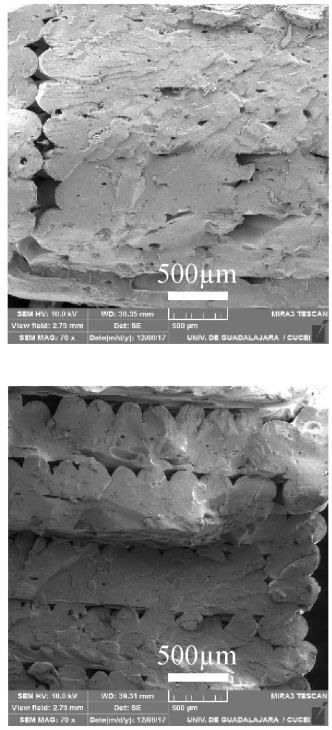

$10 \%$
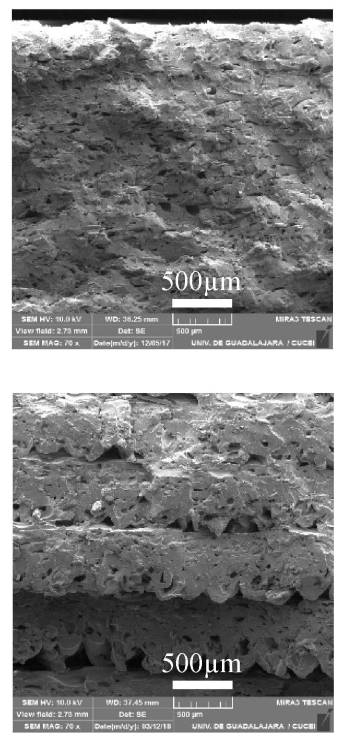

Figure 2. SEM micrographs of agave fibers/PLA biocomposites with different agave fiber content $(0,3,5$ and $10 \mathrm{wt} \%)$ and angle deposition $\left(-45^{\circ} / 45^{\circ}\right.$ and $\left.0^{\circ} / 90^{\circ}\right)(70 \times$ magnification).

\subsection{FDM Deposition Angle and Agave Fiber Content}

In FDM, variables such as printing speed, printing temperature, layer thickness, and pattern, among others, directly influence the quality and mechanical properties of the final fabricated pieces [2,42]. In the present work, AF/PLA biocomposites were printed horizontally since higher mechanical properties have been reported for printed pieces in this particular direction with the presence of a contour layer in all cases $[2,43,44]$.

Figure 2 shows the SEM micrographs of the printed pieces at different printing angles and $\mathrm{AF}$ content. In pieces printed at $0^{\circ} / 90^{\circ}$, the fracture has a characteristic transverse 
shape, parallel to the printing threads. The layer thickness value obtained at $0^{\circ} / 90^{\circ}$ was close to the specified printing value $(0.3 \mathrm{~mm})$ and diminished to $0.26 \mathrm{~mm}$ when the AF content increased to $10 \mathrm{wt} \%$. The thickness at $-45^{\circ} / 45^{\circ}$ had an average of $0.27 \mathrm{~mm}$ (Table S1, Supplementary Materials). However, the thicknesses of the AF/PLA biocomposites printed at $-45^{\circ} / 45^{\circ}$ were measured with a higher error due to the fusion of the adjacent layers. In addition, a change in morphology was observed in specimens printed using both configurations $-45^{\circ} / 45^{\circ}$ and $0^{\circ} / 90^{\circ}$, which is directly proportional to the increase in fiber content.

Table 1. Thermal properties and crystallinity values of the filaments.

\begin{tabular}{cccccccc}
\hline Filament & $\begin{array}{c}\text { Agave Fiber } \\
\text { Content }(\mathbf{w t} \%)\end{array}$ & $\mathbf{T}_{\mathbf{g}}\left({ }^{\circ} \mathbf{C}\right)$ & $\mathbf{T}_{\mathbf{c c}}\left({ }^{\circ} \mathbf{C}\right)$ & $\mathbf{T}_{\mathbf{m}}\left({ }^{\circ} \mathbf{C}\right)$ & $\mathbf{\Delta H}_{\mathbf{c c}}\left(\mathbf{J} \mathbf{g}^{-1}\right) *$ & $\mathbf{\Delta H}_{\mathbf{m}}\left(\mathbf{J} \mathbf{g}^{-1}\right) *$ & $\begin{array}{c}\text { Crystallinity } \\
(\mathbf{\%})\end{array}$ \\
\hline Neat PLA & & 58.9 & 95.9 & 168.0 & 33.7 & 44.5 & 11.6 \\
\hline \multirow{2}{*}{ Agave } & 0 & 59.1 & 91.2 & 168.9 & 25.8 & 48.0 & 23.7 \\
fiber/PLA & 3 & 57.9 & 91.8 & 169.3 & 25.3 & 46.1 & 22.9 \\
filament & 5 & 57.7 & 85.2 & 168.0 & 12.6 & 49.7 & 41.7 \\
& 10 & 57.2 & 84.7 & 169.0 & 11.4 & 48.5 & 44.1 \\
\hline
\end{tabular}

* The enthalpy values were normalized for the polymer content.

\subsection{Density and Porosity of Agave-Fiber/PLA Printed Biocomposites}

Printed biocomposites with $0 \mathrm{wt} \%$ AF/PLA showed $7 \%$ and $7.5 \%$ porosity attributed to the interstices formed between the printing threads in the FDM process (Table 2). This issue is intrinsically related to the FDM technique, and the presence of voids is expectedly higher than the obtained with pieces fabricated with other processing methods, such as injection molding [24]. In addition to the process parameters, variables such as material composition, printing angle, and printing speed greatly influence the final porosity of the biocomposites. For example, the porosity values of 3D-printed carbon fibers in ABS composites were found to be highly dependent on the printing angle, and specimens printed at $0^{\circ} / 90^{\circ}$ showed much more porosity compared to specimens printed at $-45^{\circ} / 45^{\circ}$ [45] In this work, the highest AF content tested for AF/PLA biocomposites printed at $-45^{\circ} / 45^{\circ}$ caused an increase in porosity by 2.8 -fold $(7.0 \% \pm 1.9$ to $20.1 \% \pm 0.5$ for biocomposites with $0 \mathrm{wt} \%$ and $10 \mathrm{wt} \% \mathrm{AF}$, respectively) and 2.9-fold for biocomposites printed at $0^{\circ} / 90^{\circ}$ ( $7.5 \% \pm 0.8$ to $21.9 \% \pm 1.3$ for biocomposites with $0 \mathrm{wt} \%$ and $10 \mathrm{wt} \% \mathrm{AF}$, respectively). Thus, higher concentrations of AF strongly influenced the porosity of the final biocomposites rather than the raster angle. The presence of natural fibers on polymeric composites is known to induce the formation of porous structures due to the chemical incompatibility between the used materials, also known as interfacial voids [29,46]. This is expected to negatively affect the mechanical properties, as the filler capacity is reduced [47].

Table 2. Effect of agave fiber content on apparent density and porosity of the agave fibers/PLA printed pieces.

\begin{tabular}{|c|c|c|c|c|c|}
\hline \multirow{2}{*}{$\begin{array}{l}\text { Agave Fiber } \\
\text { Content (wt } \%)\end{array}$} & \multirow{2}{*}{$\begin{array}{c}\text { Theoretical } \\
\text { Density }\left(\mathrm{g} \mathrm{cm}^{-3}\right)\end{array}$} & \multicolumn{2}{|c|}{$-45^{\circ} / 45^{\circ}$} & \multicolumn{2}{|c|}{$0^{\circ} / 90^{\circ}$} \\
\hline & & $\begin{array}{c}\text { Experimental } \\
\text { Density }\left(\mathrm{g} \mathrm{cm}^{-3}\right)\end{array}$ & Porosity (\%) & $\begin{array}{c}\text { Experimental } \\
\text { Density }\left(\mathrm{g} \mathrm{cm}^{-3}\right)\end{array}$ & Porosity (\%) \\
\hline 0 & 1.247 & $1.159 \pm 0.023$ & $7.0 \pm 1.9$ & $1.153 \pm 0.009$ & $7.5 \pm 0.8$ \\
\hline 3 & 1.248 & $1.104 \pm 0.024$ & $11.5 \pm 1.9$ & $1.135 \pm 0.015$ & $9.0 \pm 1.2$ \\
\hline 5 & 1.249 & $0.989 \pm 0.016$ & $20.8 \pm 1.3$ & $1.042 \pm 0.007$ & $16.6 \pm 0.6$ \\
\hline 10 & 1.250 & $0.999 \pm 0.006$ & $20.1 \pm 0.5$ & $0.976 \pm 0.017$ & $21.9 \pm 1.3$ \\
\hline
\end{tabular}

Similarly, apparent experimental densities of biocomposites decreased with increased AF percentages for biocomposites printed at $-45^{\circ} / 45^{\circ}\left(1.159 \mathrm{~g} \mathrm{~cm}^{-3} \pm 0.023\right.$ to $0.999 \mathrm{~g} \mathrm{~cm}^{-3}$ \pm 0.006 for specimens with $0 \mathrm{wt} \%$ and $10 \mathrm{wt} \% \mathrm{AF}$, respectively $)$ and $0^{\circ} / 90^{\circ}\left(1.153 \mathrm{~g} \mathrm{~cm}^{-3}\right.$ \pm 0.009 to $0.976 \mathrm{~g} \mathrm{~cm}^{-3} \pm 0.017$ for specimens with $0 \mathrm{wt} \%$ and $10 \mathrm{wt} \% \mathrm{AF}$, respectively) (Table 2). The presence of voids and fibers can be observed in Figures S4 and S5, Sup- 
plementary Materials. As the mass fraction of the AF is lower compared to the mass fraction of PLA, the global contribution of fibers in the density of the biocomposites is not significant; therefore, the density of the composite is expected to be similar to that of PLA (1.246 and $1.278 \mathrm{~g} \mathrm{~cm}^{-3}$, respectively). However, the density value of AF is still significantly lower than that of conventional reinforcements, such as fiberglass (density value of $2.55 \mathrm{~g} \mathrm{~cm}^{-3}$ ) [48]. Pérez-Fonseca et al. produced biocomposites with $\mathrm{AF}$ and pine fiber with polypropylene as the matrix, reporting that as the natural fiber content increased, the density of the fabricated composite also decreased [49].

\subsection{Water Absorption}

Water absorption is a process where multiple factors intervene, such as the homogeneity of the sample, the presence of fibers, and the presence of voids within the pieces [50]. Specimens fabricated from PLA can be susceptible to increased water absorption, as the polar bonds of PLA may decompose in the presence of water, thus changing the mechanical properties of the final piece [51]. Figure 3 shows the gained weight versus $t^{1 / 2}$ curves of FDM printed AF/PLA biocomposites at different percentages and two printing angles. A rapid increase in water absorption is observed until $150 \mathrm{~h}$, followed by a saturation after $1225 \mathrm{~h}$, except for 5 and $10 \mathrm{wt} \%$ AF/PLA biocomposites. A similar behavior is also observed for biocomposites of kenaf bast fiber and PLA [52]. A strong correlation of the printing angle with water absorption is observed for biocomposites with $3 \%$ and $5 \% \mathrm{AF}$. In these cases, the water absorption was superior for pieces printed at $-45^{\circ} / 45^{\circ}$. In contrast, for $10 \mathrm{wt} \% \mathrm{AF} / \mathrm{PLA}$ biocomposites printed at $0^{\circ} / 90^{\circ}$, the water uptake was higher than that for biocomposites printed at $-45^{\circ} / 45^{\circ}$. Natural fibers can form gaps, voids, and cracks because of fiber swelling. Thus, water is expected to flow through the gaps via capillary action [52]. This could explain the increased values of water uptake showed for specimens with $10 \mathrm{wt} \%$ AF.

The -OH groups of AF should increase the hydrophilicity of the final material, as these groups attract water molecules via hydrogen and van der Waals bonds [53]. This effect was observed with sisal fiber/PLA biocomposites, which showed a 3.7-fold increase in water absorption compared to neat PLA, due to the presence of the highly hydrophilic sisal fibers [54]. Similarly, Le Duigou et al. demonstrated that increasing porous structures and voids have a more pronounced effect on water absorption than the sole presence of natural fibers [55]. However, we observed that water uptake values did not correlate with increasing AF content. Instead, the tendency matched the amount of porosity present in the material, which in turn correlated with the printing angle.

\subsection{Tensile Properties}

Increasing fiber content caused a decrease in the tensile properties of 3D-printed AF/PLA biocomposites, as shown in Figure 4. FDM printed biocomposites with $0 \mathrm{wt} \% \mathrm{AF}$ had similar tensile strength and modulus values for both printed angles ( 51 MPa). The lowest tensile strength value was recorded for biocomposites with $5 \mathrm{wt} \% \mathrm{AF}$ at $-45^{\circ} / 45^{\circ}$ $(31 \mathrm{MPa})$, and biocomposites with $10 \mathrm{wt} \% \mathrm{AF} / \mathrm{PLA}$ at $0^{\circ} / 90^{\circ}(28 \mathrm{MPa})$, which represents a 1.8-fold decrease in the tensile strength compared to neat PLA pieces.

It should be noted that the tensile strength values obtained for $10 \mathrm{wt} \% \mathrm{AF} / \mathrm{PLA}$ printed biocomposites (28 MPa) are higher compared to the values of biocomposites processed with different techniques, i.e., compression molding of AF/PHB (14 MPa) and AF/LMDPE biocomposites (13 MPa) [28,56]. In contrast, compared to other natural fiber fillers for FDM processes, AF are better filler options than wood flour/PLA composites [20], wood/PLA composites [21], and cork/PLA composites [23]. Nevertheless, the mechanical behavior of AF/PLA is lower compared to reinforced sugarcane bagasse fiber/PLA biocomposites (tensile strength of $55 \mathrm{MPa}$ with $6 \mathrm{wt} \%$ fiber content) [57].

Similarly, the tensile modulus decreased with the increasing AF content of printed specimens at $0^{\circ} / 90^{\circ}$. At $10 \mathrm{wt} \% \mathrm{AF}$, the tensile value was 1.25 -fold lower $(880 \mathrm{MPa})$ compared to that of $0 \mathrm{wt} \% \mathrm{AF}$. For specimens printed at $-45^{\circ} / 45^{\circ}$, the tensile modulus 
values decreased from 0 to $5 \mathrm{wt} \%$, reaching a minimum at $5 \mathrm{wt} \% \mathrm{AF}$ ( $825 \mathrm{MPa}$ ). Finally, at $10 \mathrm{wt} \% \mathrm{AF}$ content, the tensile modulus value increased by 1.1-fold (900 $\mathrm{MPa})$ in comparison to specimens with $5 \mathrm{wt} \% \mathrm{AF}$.

The addition of natural fibers is expected to increase the stiffness (tensile modulus) of a given composite as observed by compression and injection techniques [40,56]. Tensile modulus values for PLA are around 1700 MPa processed by rotational molding [29,38], and $2300 \mathrm{MPa}$ for injection [40,58]. By FDM, a lower tensile modulus value was obtained for neat PLA (1100 $\mathrm{mPa})$, probably due to a higher porosity and a different crystallinity value of the final material caused by the FDM process [59].
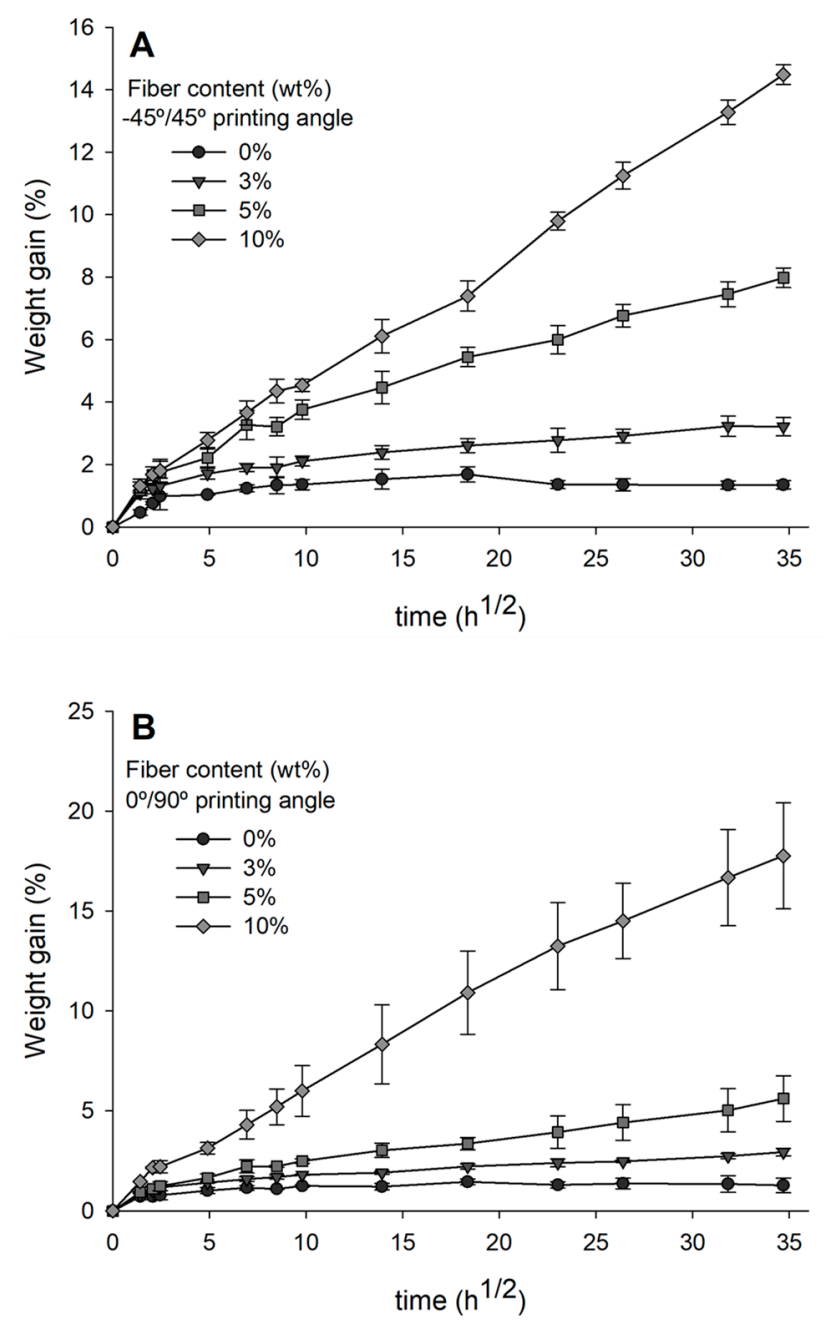

Figure 3. Water absorption of agave fibers/PLA printed biocomposites at different agave fiber percentages $(0,3,5$, and $10 \mathrm{wt} \%)$ and (A) printing angle of $-45^{\circ} / 45^{\circ}$, and (B) printing angle of $0^{\circ} / 90^{\circ}$.

\subsection{Flexural Properties}

Figure 5 shows the obtained flexural properties for AF/PLA biocomposites at different raster angles. In general, the addition of fibers had a detrimental effect on the flexural strength values, regardless of the printing angle. The maximum flexural strength value was observed when no AF were used ( $0 \mathrm{wt} \%$ AF biocomposites, 87 and $82 \mathrm{MPa}$ for $-45^{\circ} / 45^{\circ}$ and $0^{\circ} / 90^{\circ}$, respectively), followed by biocomposites with $3 \mathrm{wt} \% \mathrm{AF}$ for both printing angles (79 and $77 \mathrm{MPa}$ for $-45^{\circ} / 45^{\circ}$ and $0^{\circ} / 90^{\circ}$, respectively). The flexural strength values of biocomposites printed at $-45^{\circ} / 45^{\circ}$ with $5 \mathrm{wt} \%$ and $10 \mathrm{wt} \% \mathrm{AF} / \mathrm{PLA}$ decreased by $28 \mathrm{MPa}$ compared to biocomposites with $0 \mathrm{wt} \%$ AF (87 MPa compared to $59 \mathrm{MPa}$ ). Biocomposites printed at $0^{\circ} / 90^{\circ}$ with $10 \mathrm{wt} \% \mathrm{AF}$ showed the lowest flexural strength value recorded $(51 \mathrm{MPa})$, which represents a 1.7-fold decrease compared to biocomposites 
printed at the same angle and no fibers present. Similar results have been observed for 3Dprinted sugarcane bagasse fiber/PLA composites [57] and rice straw/ABS composites [42], where flexural properties decrease as fiber concentration increases.
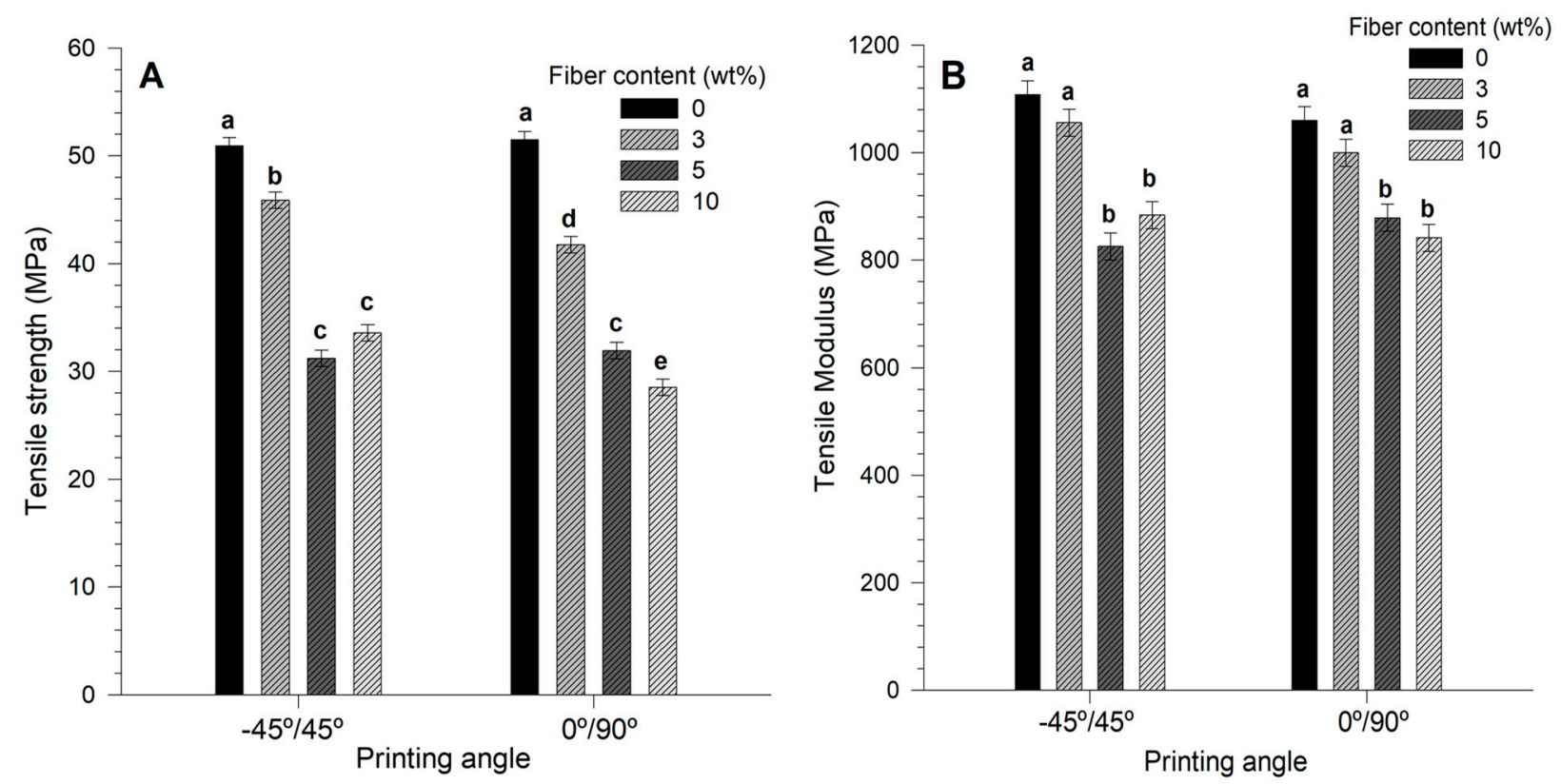

Figure 4. (A) Tensile strength and (B) tensile modulus of printed agave fibers/PLA biocomposites. The letters a-e on top of the bars indicates significant differences $(p<0.05)$.
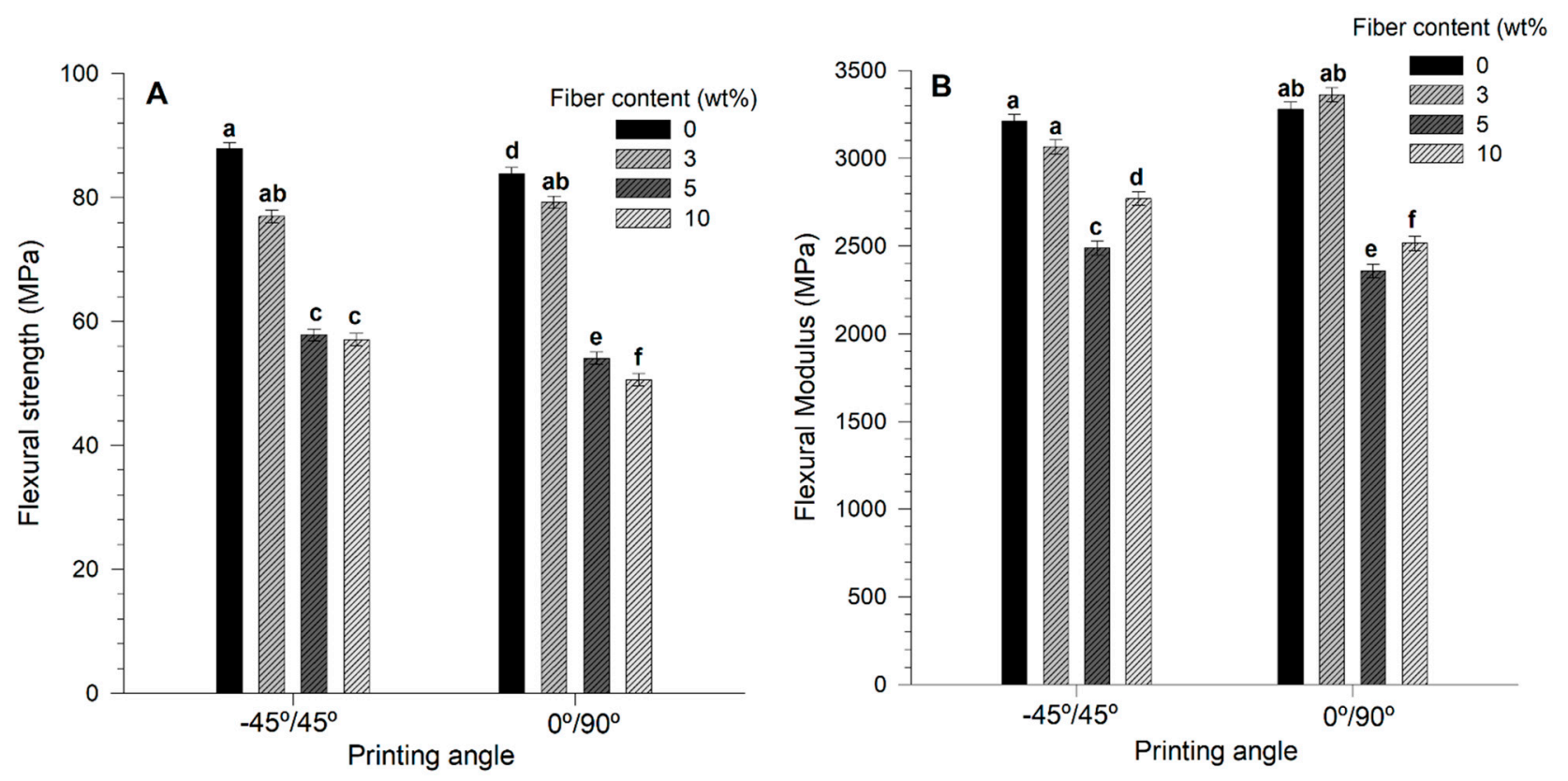

Figure 5. (A) Flexural strength and (B) flexural modulus of printed agave fibers/PLA biocomposites. The letters a-f on top of the bars indicates significant differences $(p<0.05)$.

Similarly, the flexural modulus diminished with the addition of fibers, and the recorded values were similar for both raster angles. At $-45^{\circ} / 45^{\circ}, 0 \mathrm{wt} \%$, and $3 \mathrm{wt} \%$ AF/PLA biocomposites showed flexural modulus values around $3100 \mathrm{MPa}$, while the minimum flexural modulus value of $2500 \mathrm{MPa}$ was obtained with $5 \%$ AF pieces. However, $3 \mathrm{wt} \% \mathrm{AF} / \mathrm{PLA}$ biocomposites printed at $0^{\circ} / 90^{\circ}$ showed an increase by $94 \mathrm{MPa}$ in the flexural modulus compared with biocomposites with $0 \mathrm{wt} \%$ AF/PLA (3374 compared to 
$3280 \mathrm{MPa})$. The lowest flexural modulus value (2350 MPa) was observed for specimens printed with $5 \mathrm{wt} \% \mathrm{AF}$ and $0^{\circ} / 90^{\circ}$.

Although $0 \mathrm{wt} \%$ AF/PLA biocomposites showed flexural strength values slightly lower than those reported in the literature for different processing techniques, the obtained flexural modulus values were higher than the tendency observed for PLA pieces produced via other techniques, such as injection, rotational molding, and compression $(2300,3700$ and $3100 \mathrm{MPa}$, respectively) [29,38,40].

The flexural properties observed for the biocomposites printed in this work showed no dependence with the printing angle. However, other authors have observed a correlation between printing angle and tensile and flexural strength, with a general decrease in the values from $-45^{\circ} / 45^{\circ}$ to $0^{\circ} / 90^{\circ}$. For pieces printed at $0^{\circ} / 90^{\circ}$, only the layers printed at $0^{\circ}$ with respect to the axis are those that support the tensile test, while the ones at $90^{\circ}$ had a minor effect opposing the pulling forces [59]. This behavior could be because for both printing angles $\left(-45^{\circ} / 45^{\circ}\right.$ and $\left.0^{\circ} / 90^{\circ}\right)$, a network of wires is formed perpendicularly to each angle, which achieves a similar load distribution [60]. When pieces were built at a single angle through all the layers, the load was distributed differently. Cole et al. (2016b) produced pieces by varying the printing angle and found that pieces printed at $0^{\circ}$ showed greater tensile strength after those manufactured at $45^{\circ}$ and $0^{\circ} / 90^{\circ}$, which may be because, at $0^{\circ}$, the printing threads are oriented parallel to the applied load [44].

\subsection{Impact Properties}

In Figure 6, the impact strength for AF/PLA biocomposites as a function of AF content and raster angle is depicted, where a positive correlation is observed for a raster angle of $-45^{\circ} / 45^{\circ}$. For biocomposites printed at $-45^{\circ} / 45^{\circ}$, the impact strength value increased by $3 \%$ for $3 \mathrm{wt} \% \mathrm{AF} /$ PLA compared to neat PLA. Increasing the AF content to $10 \mathrm{wt} \%$ decreased the impact strength by 1.1 -fold with $27 \mathrm{~J} \mathrm{~m}^{-1}$. In contrast, the impact resistance values for specimens printed at $0^{\circ} / 90^{\circ}$ decreased steadily with increased $\mathrm{AF}$ content, reaching a minimum value of $26 \mathrm{~J} \mathrm{~m}^{-1}$, with no significant difference compared to the $10 \mathrm{wt} \%$ AF/PLA printed at $-45^{\circ} / 45^{\circ}$.

The properties of a biocomposite rely on the chemical and physical nature of matrix and fibers. Increasing the fiber content in the AF/PLA biocomposites obtained in this work decreased the impact resistance of the material. This is explained by a low fiber-matrix compatibility causing defects and stress regions, which can be enhanced by the use of short fibers $[24,29]$.

In our case, this phenomenon was more pronounced with pieces printed at $0^{\circ} / 90^{\circ}$, with half of the printing threads in a parallel position to the crack propagation, which absorbs less energy [61].

\subsection{Disintegration under Simulated Composting Conditions}

The simulated composted conditions for specimens printed at $-45^{\circ} / 45^{\circ}$ showed no changes in weight during the initial 15 days of the experiment (Figure 7), which could be attributed to microbial lag and the adaptation to the hydrolysis of PLA chains, while the small changes observed are attributed to weighting errors. After 21 days of composting, losses of $5 \%$ in weight for 0,3 , and $5 \mathrm{wt} \%$ AF/PLA were observed, while $10 \mathrm{wt} \%$ AF/PLA pieces showed a lag phase. These changes can be explained by the generation of small oligomers and PLA monomers, which can be metabolized by microorganisms present in the compost material. After 35 days, the weight loss was around $15 \%$ for all the printed biocomposites, with no statistical differences. After 49 days of composting, $0 \mathrm{wt} \%$ AF/PLA biocomposites showed the maximum weight loss ( 27\% weight loss), followed by biocomposites with $5 \mathrm{wt} \%$ and $10 \mathrm{wt} \% \mathrm{AF}$ ( 17\% weight loss). In contrast, printed biocomposites with $3 \mathrm{wt} \%$ AF had an average of $22 \%$ weight loss; however, the standard deviation observed was $6 \%$. The total weight loss after 50 days of $10 \mathrm{wt} \%$ AF/PLA specimens was 1.6-fold less than the weight loss observed for neat PLA specimens. These results can be attributed to an increased crystallinity observed with increased AF contents, as crystalline 
regions are less susceptible to degradation than amorphous regions [62,63]. Similarly, Dong et al. obtained zero net weight losses with coir fiber/PLA from 6 to 12 days, with an $18.1 \%$ reduction in weight loss after 18 days [64]. In this case, the presence of coir fibers increased the weight loss up to $34.9 \%$, due to the high hydrophilicity of the final composites. Under environmental conditions, the decomposition of PLA to carbon dioxide, water, and methane can take from several months up to 2 years [50]. On the other hand, the fact that the composites based on AF presented a preserved structure after the composting test could be associated with an increased PLA crystallinity and stiffness by thermal annealing at the test conditions $\left(58^{\circ} \mathrm{C}\right)$ [40]. A brittle PLA could explain the high fragmentation of samples; in this case, the AF helped to keep the physical structure of the composite samples, without compromising their biodegradability.

Additional optical micrographs of the disintegration of the pieces are shown in Figure S6, Supplementary Materials.

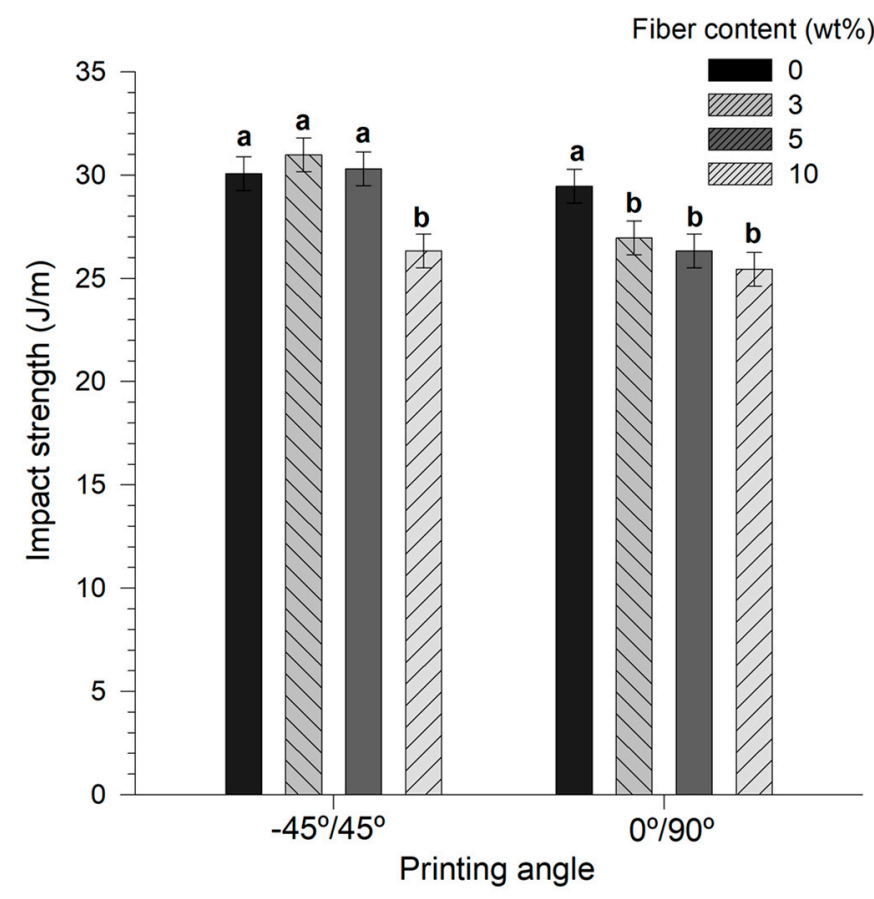

Figure 6. Charpy impact strength of printed agave fibers/PLA biocomposites. The letters a-b on top of the bars indicates significant differences $(p<0.05)$. 

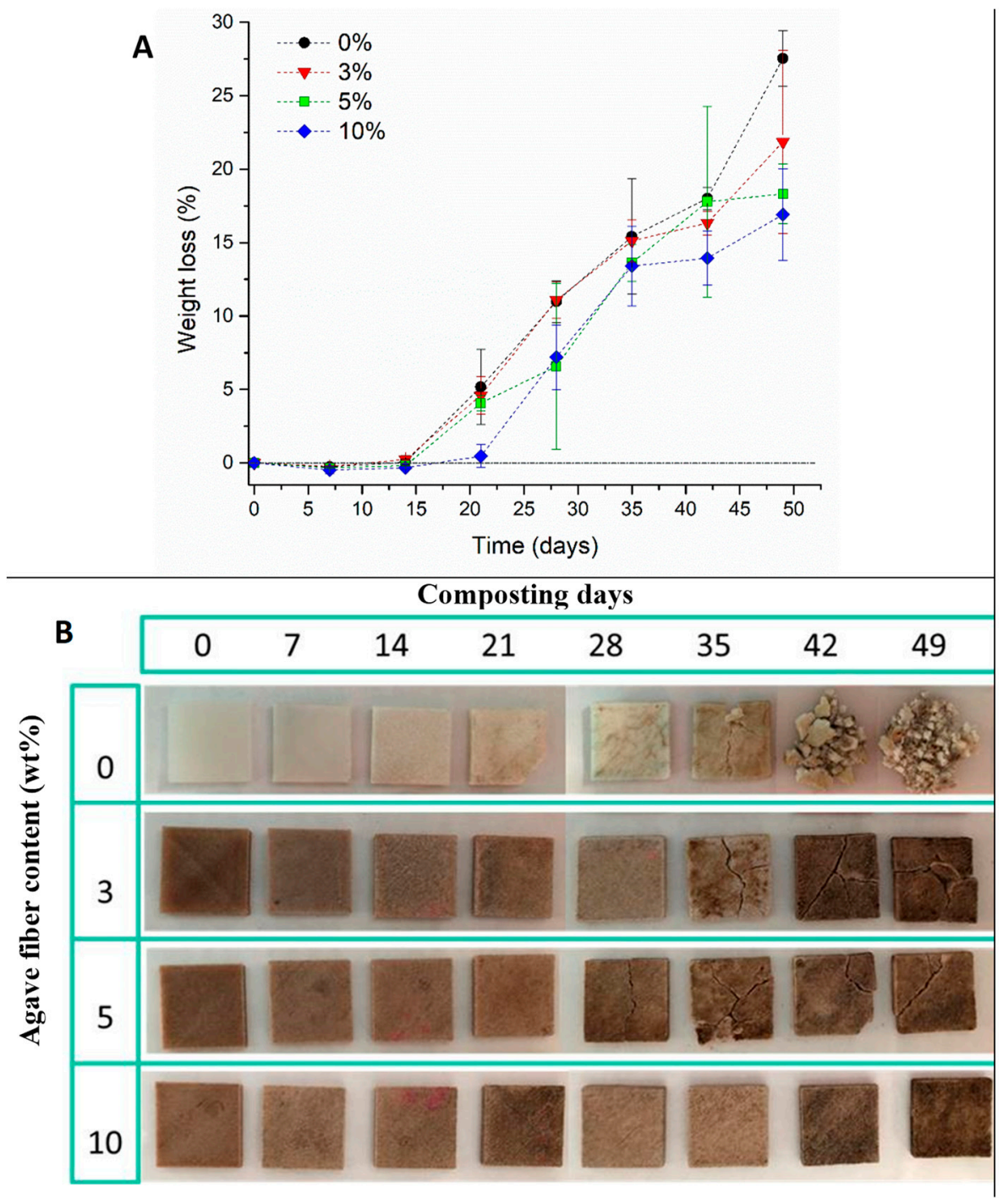

Figure 7. (A) Percentage weight losses of agave fiber/PLA printed biocomposites under simulated composting conditions and (B) photographs of agave fiber/PLA pieces after being composted.

\section{Conclusions}

In this work, AF were extruded with PLA and the filaments were employed to prepare AF/PLA biocomposites by FDM. After the extrusion process, the AF suffered mechanical damage as the fiber diameter was reduced. The results herein indicated that the fiber content, rather than the raster angle, strongly influenced the crystallinity, porosity, flexural and strength properties of the final biocomposites. In contrast, the raster angle influenced the morphology and impact resistance of the printed biocomposites. This is highly significant for future fabrications with FDM, as the choice of the natural fiber, with inherent features, as well as the thermoplastic polymer, ultimately affects the characteristics and applicability of the final piece. The fabricated AF/PLA printed biocomposites in this study have proven to be a low-cost and compostable biocomposite, with lower disintegration rate and density (lightweight). This feature can be useful for the fabrication of molds and 3D printing support materials based on $\mathrm{AF}$, such as toys, which could be easily discarded and composted after use.

Although further research is needed, AF can be employed as a component for 3D printing, and the filling of PLA composites with natural fibers is an attractive, compostable, and environmentally friendly alternative over traditional filler materials. 
Supplementary Materials: The following are available online at https:/ / www.mdpi.com/article/10

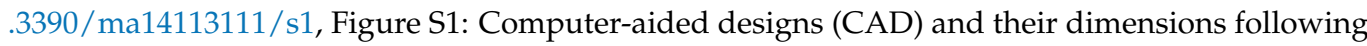
the ASTM standards for A) water absorption and biodegradation tests, (B) tensile tests, (C) flexural tests, and D) impact tests; Figure S2: Load direction applied on the specimens with respect to the printing angle for the different mechanical tests. (A) tensile, (B) flexural, and (C) impact; Figure S3: Differential scanning calorimetry (DSC) thermograms of first heating for raw PLA and agave fiber filaments; Figure S4: Scanning electron microscope (SEM) micrographs of the printed pieces showing the presence of voids and fibers; Figure S5: Scanning electron microscope (SEM) micrographs of agave fiber/PLA biocomposites printed at $-45^{\circ} / 45^{\circ}$ showing agave fiber details. (A) $0 \mathrm{wt} \%$ agave fiber/PLA biocomposites, (B) $3 \mathrm{wt} \%$ agave fiber/PLA biocomposites, (C) $5 \mathrm{wt} \%$ agave fiber/PLA biocomposites, and (D) $10 \mathrm{wt} \%$ agave fiber/PLA biocomposites; Figure S6: Optical micrographs of agave fiber/PLA biocomposite pieces under simulated composting conditions obtained after being weighed. Table S1: Formulation of biocomposites; Table S2: Layer thickness in cm for 3D-printed agave fiber/PLA biocomposites at $-45^{\circ} / 45^{\circ}$ and $0^{\circ} / 90^{\circ}$ measured from SEM micrographs.

Author Contributions: Conceptualization, V.F.-V. and L.C.R.-R.; methodology, V.F.-V., J.R.R.-O. and L.C.R.-R.; software, V.F.-V., J.R.R.-O. and L.C.R.-R.; validation, E.O.C.-L., P.O.-G., J.R.R.-O. and L.C.R.-R.; formal analysis, V.F.-V., J.R.R.-O., E.O.C.-L., T.D.-V. and L.C.R.-R.; investigation, V.F.-V., E.O.C.-L., and L.C.R.-R.; resources, E.O.C.-L., E.J.L.-N., P.O.-G., J.R.R.-O. and L.C.R.-R.; data curation, V.F.-V. and L.C.R.-R.; writing-original draft preparation, T.D.-V. and L.C.R.-R.; writing-review and editing, T.D.-V. and L.C.R.-R.; visualization, V.F.-V., T.D.-V. and L.C.R.-R.; supervision, J.R.R.-O. and L.C.R.-R.; project administration, L.C.R.-R.; funding acquisition, E.J.L.-N., P.O.-G., J.R.R.-O. and L.C.R.-R. All authors have read and agreed to the published version of the manuscript.

Funding: This research received no external funding. The authors are grateful to CONACYT and Universidad de Guadalajara for the economic support. V.F.-V. would like to thank Consejo Nacional de Ciencia y Tecnología (CONACYT) for her Ph.D. scholarship. We gratefully recognize a postdoctoral fellowship for T.D.-V. from postdoctoral grants SEP-SES (23-007-C).

Institutional Review Board Statement: Not applicable.

Informed Consent Statement: Not applicable.

Data Availability Statement: The data presented in this study are available on request from the corresponding author.

Conflicts of Interest: The authors declare no conflict of interest.

\section{References}

1. Matsuzaki, R.; Ueda, M.; Namiki, M.; Jeong, T.K.; Asahara, H.; Horiguchi, K.; Nakamura, T.; Todoroki, A.; Hirano, Y. Threedimensional printing of continuous-fiber composites by in-nozzle impregnation. Sci. Rep. 2016, 6, 23058. [CrossRef] [PubMed]

2. Chacón, J.M.; Caminero, M.A.; García-Plaza, E.; Núñez, P.J. Additive manufacturing of PLA structures using fused deposition modelling: Effect of process parameters on mechanical properties and their optimal selection. Mater. Des. 2017, 124, 143-157. [CrossRef]

3. Ziemian, C.W.; Sharma, M.M.; Ziemian, S.N. Anisotropic Mechanical Properties of ABS Parts Fabricated by Fused Deposition Modelling. Mech. Eng. 2012, 23, 2397.

4. Turner, B.N.; Strong, R.; Gold, S.A. A review of melt extrusion additive manufacturing processes: I. Process design and modeling. Rapid Prototyp. J. 2014, 20, 192-204. [CrossRef]

5. Mohamed, O.A.; Masood, S.H.; Bhowmik, J.L. Experimental Investigations of Process Parameters Influence on Rheological Behavior and Dynamic Mechanical Properties of FDM Manufactured Parts. Mater. Manuf. Process. 2016, 31, 1983-1994. [CrossRef]

6. Mohanty, A.K.; Vivekanandhan, S.; Pin, J.M.; Misra, M. Composites from renewable and sustainable resources: Challenges and innovations. Science 2018, 362, 536-542. [CrossRef]

7. Bourmaud, A.; Beaugrand, J.; Shah, D.U.; Placet, V.; Baley, C. Towards the design of high-performance plant fibre composites. Prog. Mater. Sci. 2018, 97, 347-408. [CrossRef]

8. Chia, H.N.; Wu, B.M. Recent advances in 3D printing of biomaterials. J. Biol. Eng. 2015, 9, 4. [CrossRef]

9. Lee Ventola, C. Medical applications for 3D printing: Current and projected uses. Pharm. Ther. 2014, 39, 704-711.

10. Gregor, A.; Filová, E.; Novák, M.; Kronek, J.; Chlup, H.; Buzgo, M.; Blahnová, V.; Lukášová, V.; Bartoš, M.; Nečas, A.; et al. Designing of PLA scaffolds for bone tissue replacement fabricated by ordinary commercial 3D printer. J. Biol. Eng. 2017, 11, 31. [CrossRef]

11. Boparai, K.S.; Singh, R.; Singh, H. Development of rapid tooling using fused deposition modeling: A review. Rapid Prototyp. J. 2016, 22, 281-299. [CrossRef]

12. Mellinas, C.; Ramos, M.; Jiménez, A.; Garrigós, M.C. Recent trends in the use of pectin from agro-waste residues as a natural-based biopolymer for food packaging applications. Materials 2020, 13, 673. [CrossRef] 
13. Cataldo, V.A.; Cavallaro, G.; Lazzara, G.; Milioto, S.; Parisi, F. Coffee grounds as filler for pectin: Green composites with competitive performances dependent on the UV irradiation. Carbohydr. Polym. 2017, 170, 198-205. [CrossRef]

14. Ciapponi, R.; Turri, S.; Levi, M. Mechanical reinforcement by microalgal biofiller in novel thermoplastic biocompounds from plasticized gluten. Materials 2019, 12, 1476. [CrossRef]

15. Rasal, R.M.; Janorkar, A.V.; Hirt, D.E. Poly(lactic acid) modifications. Prog. Polym. Sci. 2010, 35, 338-356. [CrossRef]

16. Kumar Bajpai, P.; Singh, I.; Madaan, J. Development and characterization of PLA-based green composites: A review. J. Thermoplast. Compos. Mater. 2014, 27, 52-81. [CrossRef]

17. Marimuthu, D.; Rajesh, K.; Ravikumar, S.M. Applications of CT/CAD/RPT in the futuristic development of orthopaedics and fabrication of plate and screw material from natural fiber particle reinforced composites for humerus bone fixation-A future drift. Malays. J. Educ. Technol. 2010, 10, 73-81.

18. Abdul Khalil, H.P.S.; Bhat, A.H.; Ireana Yusra, A.F. Green composites from sustainable cellulose nanofibrils: A review. Carbohydr. Polym. 2012, 87, 963-979. [CrossRef]

19. Zhao, D.; Cai, X.; Shou, G.; Gu, Y.; Wang, P. Study on the preparation of bamboo plastic composite intend for additive manufacturing. Key Eng. Mater. 2016, 667, 250-258. [CrossRef]

20. Tao, Y.; Wang, H.; Li, Z.; Li, P.; Shi, S.Q. Development and application of wood flour-filled polylactic acid composite filament for 3D printing. Materials 2017, 10, 339. [CrossRef] [PubMed]

21. Martikka, O.; Kärki, T.; Wu, Q. Mechanical properties of 3D-printed wood-plastic composites. Key Eng. Mater. 2018, 777, 499-507. [CrossRef]

22. Gkartzou, E.; Koumoulos, E.P.; Charitidis, C.A. Production and 3D printing processing of bio-based thermoplastic filament. Manuf. Rev. 2017, 4, 1. [CrossRef]

23. Daver, F.; Lee, K.P.M.; Brandt, M.; Shanks, R. Cork-PLA composite filaments for fused deposition modelling. Compos. Sci. Technol. 2018, 168, 230-237. [CrossRef]

24. Mazzanti, V.; Malagutti, L.; Mollica, F. FDM 3D printing of polymers containing natural fillers: A review of their mechanical properties. Polymers 2019, 11, 1094. [CrossRef] [PubMed]

25. López-López, A.; Davila-Vazquez, G.; León-Becerril, E.; Villegas-García, E.; Gallardo-Valdez, J. Tequila vinasses: Generation and full scale treatment processes. Rev. Environ. Sci. Biotechnol. 2010, 9, 109-116. [CrossRef]

26. Consejo Regulador de Tequila. Available online: https://www.crt.org.mx/EstadisticasCRTweb/ (accessed on 1 February 2021).

27. Hulle, A.; Kadole, P.; Katkar, P. Agave Americana leaf fibers. Fibers 2015, 3, 64-75. [CrossRef]

28. Torres-Tello, E.V.; Robledo-Ortíz, J.R.; González-García, Y.; Pérez-Fonseca, A.A.; Jasso-Gastinel, C.F.; Mendizábal, E. Effect of agave fiber content in the thermal and mechanical properties of green composites based on polyhydroxybutyrate or poly(hydroxybutyrate-co-hydroxyvalerate). Ind. Crops Prod. 2017, 99, 117-125. [CrossRef]

29. Cisneros-López, E.O.; Pérez-Fonseca, A.A.; González-García, Y.; Ramírez-Arreola, D.E.; González-Núñez, R.; Rodrigue, D.; Robledo-Ortíz, J.R. Polylactic acid-agave fiber biocomposites produced by rotational molding: A comparative study with compression molding. Adv. Polym. Technol. 2018, 37, 2528-2540. [CrossRef]

30. Pérez-Fonseca, A.A.; Gómez, C.; Dávila, H.; González-Núñez, R.; Robledo-Ortíz, J.R.; Vázquez-Lepe, M.O.; Herrera-Gómez, A. Chitosan Supported onto Agave Fiber-Postconsumer HDPE Composites for Cr(VI) Adsorption. Ind. Eng. Chem. Res. 2012, 51, 5939-5946. [CrossRef]

31. User's Guide TRIOS Software; TA Instruments: New Castle, DE, USA, 2018.

32. Zhao, H.; Cui, Z.; Sun, X.; Turng, L.S.; Peng, X. Morphology and properties of injection molded solid and microcellular polylactic acid/polyhydroxybutyrate-valerate (PLA/PHBV) blends. Ind. Eng. Chem. Res. 2013, 52, 2569-2581. [CrossRef]

33. SketchUp Support. Available online: https:/ / help.sketchup.com/en/sketchup/sketchup (accessed on 2 June 2021).

34. Repetier-Host Software documentation. Available online: https://www.repetier.com/documentation/repetier-host (accessed on 2 June 2021).

35. Alam, A.K.M.M.; Mina, M.F.; Beg, M.D.H.; Mamun, A.A.; Bledzki, A.K.; Shubhra, Q.T.H. Thermo-mechanical and morphological properties of short natural fiber reinforced poly (lactic acid) biocomposite: Effect of fiber treatment. Fibers Polym. 2014, 15, 1303-1309. [CrossRef]

36. User's Guide STATGRAPHICS Centurion XV; StatPoint Inc: The Plains, VA, USA, 2005.

37. Vaxman, A.; Narkis, M.; Siegmann, A.; Kenig, S. Short-fiber-reinforced thermoplastics. Part III: Effect of fiber length on rheological properties and fiber orientation. Polym. Compos. 1989, 10, 454-462. [CrossRef]

38. Yang, Z.; Feng, X.; Bi, Y.; Zhou, Z.; Yue, J.; Xu, M. Bleached extruder chemi-mechanical pulp fiber-PLA composites: Comparison of mechanical, thermal, and rheological properties with those of wood flour-PLA bio-composites. J. Appl. Polym. Sci. 2016, 133, 1-9. [CrossRef]

39. De Meo, A.; De Santis, F.; Pantani, R. Effects of rapid cavity temperature variations on the crystallinity of PLA. In Proceedings of the AIP Conference Proceedings, Cesme-Izmir, Turkey, 26-30 May 2019; American Institute of Physics Inc.: College Park, MD, USA, 2020; Volume 2205, p. 020016.

40. Pérez-Fonseca, A.A.; Robledo-Ortíz, J.R.; González-Núñez, R.; Rodrigue, D. Effect of thermal annealing on the mechanical and thermal properties of polylactic acid-cellulosic fiber biocomposites. J. Appl. Polym. Sci. 2016, 133, 1-9. [CrossRef]

41. Teixeira, E.d.M.; Curvelo, A.A.S.; Corrêa, A.C.; Marconcini, J.M.; Glenn, G.M.; Mattoso, L.H.C. Properties of thermoplastic starch from cassava bagasse and cassava starch and their blends with poly (lactic acid). Ind. Crops Prod. 2012, 37, 61-68. [CrossRef] 
42. Osman, M.A.; Atia, M.R.A. Investigation of ABS-rice straw composite feedstock filament for FDM. Rapid Prototyp. J. 2018, 24, 1067-1075. [CrossRef]

43. Smith, W.C.; Dean, R.W. Structural characteristics of fused deposition modeling polycarbonate material. Polym. Test. 2013, 32, 1306-1312. [CrossRef]

44. Cole, D.P.; Riddick, J.C.; Iftekhar Jaim, H.M.; Strawhecker, K.E.; Zander, N.E. Interfacial mechanical behavior of 3D printed ABS. J. Appl. Polym. Sci. 2016, 133, 1-12. [CrossRef]

45. Zhang, W.; Wu, A.S.; Sun, J.; Quan, Z.; Gu, B.; Sun, B.; Cotton, C.; Heider, D.; Chou, T.W. Characterization of residual stress and deformation in additively manufactured ABS polymer and composite specimens. Compos. Sci. Technol. 2017, 150, 102-110. [CrossRef]

46. Huda, M.S.; Drzal, L.T.; Mohanty, A.K.; Misra, M. Effect of fiber surface-treatments on the properties of laminated biocomposites from poly(lactic acid) (PLA) and kenaf fibers. Compos. Sci. Technol. 2008, 68, 424-432. [CrossRef]

47. Ning, F.; Cong, W.; Qiu, J.; Wei, J.; Wang, S. Additive manufacturing of carbon fiber reinforced thermoplastic composites using fused deposition modeling. Compos. Part B Eng. 2015, 80, 369-378. [CrossRef]

48. Mohanty, A.K.; Misra, M.; Drzal, L.T. Sustainable bio-composites from renewable resources: Opportunities and challenges in the green materials world. J. Polym. Environ. 2002, 10, 19-26. [CrossRef]

49. Pérez-Fonseca, A.A.; Robledo-Ortíz, J.R.; Moscoso-Sánchez, F.J.; Rodrigue, D.; González-Núñez, R. Injection molded self-hybrid composites based on polypropylene and natural fibers. Polym. Compos. 2014, 35, 1798-1806. [CrossRef]

50. Yew, G.H.; Mohd Yusof, A.M.; Mohd Ishak, Z.A.; Ishiaku, U.S. Water absorption and enzymatic degradation of poly(lactic acid)/rice starch composites. Polym. Degrad. Stab. 2005, 90, 488-500. [CrossRef]

51. Vicente, C.M.S.; Fernandes, J.; Reis, L.; De Deus, A.M.; Vaz, M.F.; Leite, M. Effect of protective coatings on the water absorption and mechanical properties of 3D printed PLA. Frat. Integrita Strutt. 2019, 13, 748-756. [CrossRef]

52. Taib, R.M.; Ramarad, S.; Ishak, Z.A.M.; Todo, M. Water absorption and tensile properties of kenaf bast fiber-plasticized poly(lactic acid) biocomposites. In Proceedings of the Polymer Proceeding Society 24th Annual Meeting, Solerno, Italy, 15-19 June 2008; pp. 2-5.

53. Pérez-Fonseca, A.A.; Arellano, M.; Rodrigue, D.; González-Núñez, R.; Robledo-Ortíz, J.R. Effect of coupling agent content and water absorption on the mechanical properties of coir-agave fibers reinforced polyethylene hybrid composites. Polym. Compos. 2016, 37, 3015-3024. [CrossRef]

54. Rajesh, G.; Prasad, A.R.; Gupta, A. Mechanical and degradation properties of successive alkali treated completely biodegradable sisal fiber reinforced poly lactic acid composites. J. Reinf. Plast. Compos. 2015, 34, 951-961. [CrossRef]

55. Le Duigou, A.; Castro, M.; Bevan, R.; Martin, N. 3D printing of wood fibre biocomposites: From mechanical to actuation functionality. Mater. Des. 2016, 96, 106-114. [CrossRef]

56. Cisneros-López, E.O.; Anzaldo, J.; Fuentes-Talavera, F.J.; González-Núñez, R.; Robledo-Ortíz, J.R.; Rodrigue, D. Effect of agave fiber surface treatment on the properties of polyethylene composites produced by dry-blending and compression molding. Polym. Compos. 2017, 38, 96-104. [CrossRef]

57. Liu, H.; He, H.; Peng, X.; Huang, B.; Li, J. Three-dimensional printing of poly(lactic acid) bio-based composites with sugarcane bagasse fiber: Effect of printing orientation on tensile performance. Polym. Adv. Technol. 2019, 30, 910-922. [CrossRef]

58. Johari, A.P.; Mohanty, S.; Kurmvanshi, S.K.; Nayak, S.K. Influence of different treated cellulose fibers on the mechanical and thermal properties of poly(lactic acid). ACS Sustain. Chem. Eng. 2016, 4, 1619-1629. [CrossRef]

59. Dawoud, M.; Taha, I.; Ebeid, S.J. Mechanical behaviour of ABS: An experimental study using FDM and injection moulding techniques. J. Manuf. Process. 2016, 21, 39-45. [CrossRef]

60. Rezayat, H.; Zhou, W.; Siriruk, A.; Penumadu, D.; Babu, S. Structure-mechanical property relationship in fused deposition modelling. Mater. Sci. Technol. 2015, 31, 895-903. [CrossRef]

61. Es-Said, O.S.; Foyos, J.; Noorani, R.; Mendelson, M.; Marloth, R.; Pregger, B.A. Effect of Layer Orientation on Mechanical Properties of Rapid Prototyped Samples. Mater. Manuf. Process. 2000, 15, 107-122. [CrossRef]

62. Yussuf, A.A.; Massoumi, I.; Hassan, A. Comparison of polylactic acid/kenaf and polylactic acid/rise husk composites: The influence of the natural fibers on the mechanical, thermal and biodegradability properties. J. Polym. Environ. 2010, 18, 422-429. [CrossRef]

63. Iovino, R.; Zullo, R.; Rao, M.A.; Cassar, L.; Gianfreda, L. Biodegradation of poly(lactic acid)/starch/coir biocomposites under controlled composting conditions. Polym. Degrad. Stab. 2008, 93, 147-157. [CrossRef]

64. Dong, Y.; Ghataura, A.; Takagi, H.; Haroosh, H.J.; Nakagaito, A.N.; Lau, K.T. Polylactic acid (PLA) biocomposites reinforced with coir fibres: Evaluation of mechanical performance and multifunctional properties. Compos. Part A Appl. Sci. Manuf. 2014, 63, 76-84. [CrossRef] 